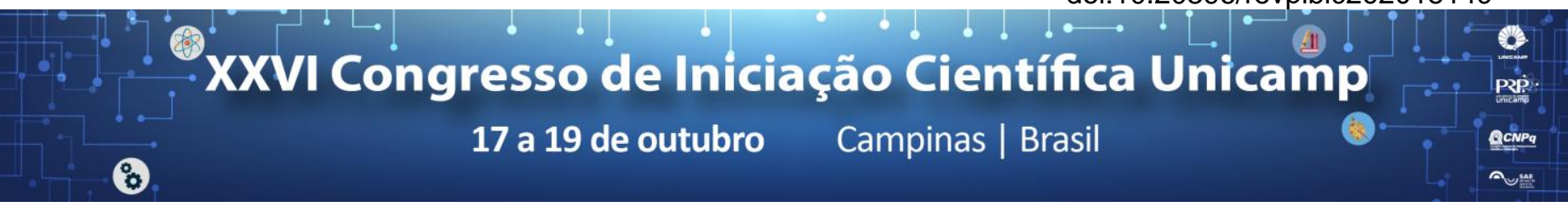

\title{
ANÁLISE POSTURAL E DA CARGA FÍSICA DE TRABALHO NA HORTICULTURA ORGÂNICA
}

\section{André Ribeiro Lacerda*, Roberto Funes Abrahão, Mauro José Andrade Tereso.}

\section{Resumo}

Este projeto visa caracterizar a carga física de trabalho na horticultura orgânica em uma jornada de trabalho. Buscou-se identificar e quantificar posturas laborais e carga de trabalho na execução das tarefas da horticultura orgânica por meio de amostragem sistemática de situações de trabalho, juntamente do software CAPTIV e com planilhas de frequências cardíacas dos trabalhadores avaliados. Esse conhecimento pode ser de valia na formulação de políticas públicas para o setor, inclusive priorizando o desenvolvimento tecnológico orientado à minimização das dificuldades laborais e ao aumento da produtividade do trabalho.

\section{Palavras-chave:}

ergonomia, horticultura orgânica, carga física de trabalho.

\section{Introdução}

A horticultura orgânica está cada vez mais em ascensão na agricultura brasileira e muito se fala nos dias atuais sobre uma alimentação saudável. $\mathrm{Em}$ sua dissertação de doutorado, Ivan Augusto Vall Ribeiro analisou a carga física de trabalho na horticultura orgânica dividindo entre os diferentes sistemas de trabalho (RIBEIRO, 2011). O presente projeto buscou caracterizar essa carga física, buscando analisar a jornada de trabalho como um todo. O projeto teve como objetivos:

Sistematizar as posturas típicas do trabalho na horticultura orgânica em uma jornada de trabalho em diferentes tarefas a partir da amostragem sistemática das situações de trabalho;

Classificar a carga física de trabalho mensurada a partir de indicadores clássicos da literatura ergonômica, como, por exemplo, o método OWAS;

Identificar a carga cardiovascular nos diferentes sistemas de trabalho e operações.

\begin{tabular}{|c|c|c|c|c|c|}
\hline \multicolumn{4}{|c|}{ Resultados e } & \multicolumn{2}{|c|}{ Discussão } \\
\hline \multirow{3}{*}{ TRONCO } & $\begin{array}{c}\text { Neraras } \\
(<20)^{2}\end{array}$ & 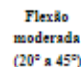 & 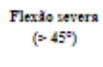 & & \\
\hline & $\stackrel{x}{\Lambda}$ & 象 & & & \\
\hline & 1 & 2 & 3 & & \\
\hline \multirow{3}{*}{ BRAços } & 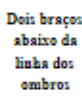 & 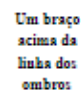 & 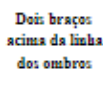 & & \\
\hline & $\stackrel{R}{h}$ & $\kappa^{\alpha}$ & co & & \\
\hline & 1 & $2^{2}$ & 3 & & \\
\hline \multirow{3}{*}{ PERNAS } & $\begin{array}{l}\text { Pernas } \\
\text { etetudidas }\end{array}$ & 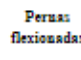 & Agrchado & Ajoesthado & Serexado \\
\hline & $\AA$ & $\Omega$ & R & 2 & $R$ \\
\hline & 1 & 2 & 3 & 4 & 5 \\
\hline
\end{tabular}

Figura 1. Registro de posturas básicas. (Fonte: Ribeiro, 2011).
Para o trabalhador 1 , obteve-se uma freqüência cardíaca de trabalho (FCT) de 94 bpm e uma carga cardiovascular (CCV) de $26,57 \%$ para a jornada de trabalho. Com esse valor de FCT, é possível afirmar, conforme classificação ASTRAND (2006), que o trabalho é moderado. Já para o trabalhador 2, obteve-se um FCT=79 bpm e $C C V=18,88 \%$. Classificando como trabalho leve. Foi observada diversas vezes a adoção de posturas severas, o que evidencia o risco de distúrbios osteomusculares. mostrou elevado, porém foi significante a diferença entre a CCV encontrado para o trabalhador 1 e a calculado para o trabalhador 2, essa diferença pode ter se destacado pelo fato de o trabalhador 1, o qual apresentou uma maior CCV, ter efetuado tratos culturais, mais especificamente a operação de capina, que acaba possuindo uma maior exigência. Isso é de grande destaque, uma vez que na horticultura orgânica brasileira, na atual conjuntura, faz-se pouco uso de mecanização, dado o pequeno espaço existente para inserção de máquinas (viés físico), o mercado de maquinário ser voltado mais para produções como soja e cana-de-açúcar (viés econômico), bem como a produção orgânica não utilizar produtos químicos.

\section{Agradecimentos}

Agradeço aos financiadores desse projeto: PIBIC/CNPq. Agradeço ao meu orientador, o Prof. Dr. Roberto Funes Abrahão e ao meu co-orientador, o Prof. Dr. Mauro José Andrade Tereso, pela orientação fornecida a mim e também agradeço ao Dr. Ivan Augusto Vall Ribeiro, que efetuou as gravações de campo utilizadas nesse projeto.

\footnotetext{
1 Astrand, P., Rodahl, Dahl, K. , Stromme, H. A. Tratado de fisiologia do trabalho: bases fisiológicas do exercício. $4^{\mathrm{a}}$ ed.São Paulo: Artmed, 2006.

${ }^{2}$ Ribeiro, Ivan Augusto Vall. Caracterização da Carga Física de Trabalho na Horticultura Orgânica. Campinas: UNICAMP, 2011
} 